\title{
Toward the modeling of Russia's monetary system
}

\author{
S. M. Borodachev
}

Institute of Economics and Management, Ural Federal University named after the First President of Russia B. N.

Yeltsin, Mira Str. 19, 620002, Ekaterinburg, Russia.

e-mail: s.m.borodachev@gmail.com

\begin{abstract}
Russia through cross-border flows of rubles and (foreign) currency and the creation of deposits by commercial banks. Volumes of flows and deposits in turn depend on changes in the currency/ruble exchange rate. It was found that the growth/fall of the USD rate by 1 RUB for the month, for the same month decreases/increases: currency outflow abroad by $\$ 0.111$ billion and creation of ruble deposits and the inflow of rubles from outside by $\$ 0.133$ billion.
\end{abstract}

\section{Keywords: broad money supply, currency outflow, money creation, exchange rate, Kalman filter}

\section{INTRODUCTION}

The economics and finances of modern Russia are deeply integrated into the global system, when rubles and currency, on equal terms, fulfill the function of money. However, for proper monetary regulation it is necessary to clearly realize their volumes and mutual transitions. From the statistics of the Central Bank's balance of payments [1], it is difficult to understand how much of which money is involved in cross-border transfer when acquiring assets or making commitments. The objective of this work: to build a framework model of the Russian monetary system, covering the most important money flows and suitable for further clarification. The basic principles of the model: rubles and currency in the accounts of residents change under the influence of foreign trade, other arrivals from the outside /creation of rubles and currency outflows, purchase and sale of currency for rubles from abroad. It is generally recognized that forecasting of exchange rates is very difficult, as information shocks and political decisions have a decisive influence on them. But the changes in exchange rate have a significant impact on the Russian monetary system and should be used as explaining variables in the model, as well as replenishment of international reserve assets of the Russian Federation, for example, at favorable oil prices.

\section{MODEL AND DATA}

Observed output in the moments (the beginning of the subsequent months) $t=0,1, \ldots, T$

$$
y^{t}=\left(\begin{array}{l}
M 2^{t} \\
M 4^{t}
\end{array}\right)
$$

where $M 2^{t}$ is the money supply in the national definition and $M 4^{t}$ is the broad money supply (consisting of $M 2^{t}$ and deposits in currency placed in the banking system by residents of the Russian Federation), billion RUB. We introduce the values: $R^{t}$ - ruble deposits (residents), $D^{t}$ - currency deposits (residents) at time $t$. ex $^{t}$ и $\mathrm{im}^{t}$ export and import of goods for the month from $t$ to $t+1, R A^{t}$ - creation of ruble deposits by commercial banks [2] + coming of rubles from the outside for the month (for example, for the purchase of Russian stocks, bonds), $D A^{t}$ - currency outflow abroad, $D R^{t}$ - purchase / sales of foreign currency for rubles from abroad during the same period (purchase / sale of currency for rubles in the 
country, obviously, does not change $R^{t}$ and $D^{t}$ ). All in billion USD. $\Delta S^{t}$ - the change in the dollar-to-ruble exchange rate $S^{t}$ during the same period (RUB for 1 USD). System dynamics

$$
\begin{aligned}
& R^{t+1}=\frac{S^{t}}{S^{t+1}} R^{t}+0.144 e^{t}-0.31 \text { im }^{t}+R A^{t}-D R^{t}+\delta_{0}^{t} \\
& D^{t+1}=D^{t}+0.856 e^{t}-0.69 \operatorname{im}^{t}-D A^{t}+D R^{t}+\beta_{1} \Delta R E S 0^{t}+\delta_{1}^{t}, \\
& R A^{t}=R A^{t-1}-\beta_{2} \Delta S^{t}+\delta_{2}^{t}, \\
& D A^{t}=D A^{t-1}-\beta_{3} \Delta S^{t}+\delta_{3}^{t}, \\
& D R^{t}=D R^{t-1}+\beta_{0} \Delta S^{t}+\delta_{4}^{t}
\end{aligned}
$$

The first coefficient on the right-hand side (1) provides a conversion to the currency of the passing part of the ruble deposits. The coefficients for export and import are taken from [3]: "if Russia receives only 14.4\% in rubles for export, then it pays $31 \%$ of import in its own currency". For clarification, you can take the actual data on rubles and currency for each month. We assume (3), that the change in magnitude $R A^{t}$ against the same month ago is proportional $\Delta S^{t}$. Similarly interpret $D A^{t}$ and $D R^{t}(4)$ - (5). The last 3 indicators are not related to $e x^{t}, i m^{t}$, and can be negative when changing the direction of the flow of the relevant money. $\delta_{i}^{t}-$ mutually independent errors. $\triangle R E S 0^{t}=\max \left(\triangle R E S^{t}, 0\right)$, $\triangle R E S^{t}=R E S^{t+1}-R E S^{t}, R E S^{t}-$ international reserve assets of the Russian Federation at time $t$ in billion USD. The meaning of the term $\beta_{1} \Delta R E S 0^{t}$ is that when the accumulation of reserves took place, then these were favorable months for the build-up $D^{t}$. An attempt to directly include the known increase / decrease of reserves in the accounts (1) and (2) worsened the description, which means that reserves are not replenished from them.

We introduce the directly unobservable state vector of the system $x^{t}=\left(\begin{array}{llll}R^{t} & D^{t} \quad R A^{t-1} \quad D A^{t-1} \quad D R^{t-1}\end{array}\right)^{T}$, and the

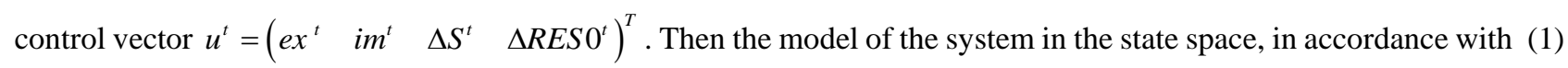
- (5) has a form

$$
\begin{gathered}
x^{t+1}=F^{t} x^{t}+G^{t} u^{t}+w^{t}, \\
y^{t}=H^{t} x^{t}+v^{t},
\end{gathered}
$$

where the operator of evolution $F^{t}$, control $G^{t}$, and observation $H^{t}$.

Monthly data from 01.01.2015 to $01.12 .2019(t=0, \ldots, 59=T)$ were taken from the website of the Central Bank of Russia [4]. See table 1. 


\begin{tabular}{|c|l|l|l|l|l|l|l|}
\hline \multicolumn{6}{|c|}{ Table 1. Data for calculations } \\
\hline$t$ & 0 & 1 & 2 & 3 & $\ldots$ & 58 & 59 \\
\hline$M 2^{t}$ & 31616 & 31034 & 31225 & 31029 & $\ldots$ & 48083 & 49195 \\
\hline$M 4^{t}$ & 42910 & 45155 & 43881 & 43204 & $\ldots$ & 61680 & 62733 \\
\hline$e x^{t}$ & 27.9 & 29.4 & 32.9 & 30.7 & $\ldots$ & 35.4 & \\
\hline$i m^{t}$ & 12.2 & 15.4 & 17.1 & 16.2 & $\ldots$ & 23.2 & \\
\hline$R E S^{t}$ & 385.5 & 376.2 & 360.2 & 356.4 & $\ldots$ & 540.9 & 542 \\
\hline$S^{t}$ & 59.233 & 69.939 & 61.781 & 58.062 & $\ldots$ & 63.873 & 64.082 \\
\hline
\end{tabular}

\section{KALMAN FILTER AND INTERPRETATION OF CALCULATION RESULTS}

Kalman filter is widely used in economic studies (see, for example, [5 - 7]). It makes it possible to evaluate the parameters of the system, evaluate and predict the unobservable characteristics of the state of the system and its output.

Model Parameters

$$
\theta=\left(\sigma v_{0} \sigma \delta \sigma_{P} \beta\right)^{T},
$$

where $\sigma \delta$ - is the vector of standard deviations of errors in (1) - (5). We choose the initial state estimate $\hat{x}^{0 \mid 0}$ (a rough assessment $)\left(\begin{array}{lllll}500 & 200 & 7 & 10 & 0\end{array}\right)^{T}$, and the covariance matrix of this estimate $\sigma_{P}^{2} I, I$ is the identity matrix. We take the covariance matrix of the observation error vector $v^{t}$ equal $R=\sigma v_{0}^{2}\left(\begin{array}{ll}1 & 1 \\ 1 & 2\end{array}\right)$.

The estimation of the vector of model parameters was carried out by minimizing the mean square sum of errors in predicting money supplies $M 2^{t}$ и $M 4^{t}$ in the fit window ( $T l$ is the initial moment, $T u$ is the final moment of the window).

$$
\begin{gathered}
\operatorname{RMSE}(\theta)=\sqrt{\frac{1}{T u-(T l-1)} \sum_{t=T l}^{T_{u}}\left\{\left[\left(y^{t}\right)_{0}-\left(\hat{y}^{\mid t-1}\right)_{0}\right]^{2}+\left[\left(y^{t}\right)_{1}-\left(\hat{y}^{t \mid t-1}\right)_{1}\right]^{2}\right\}}, \\
\hat{\theta}_{R M S E}=\underset{\hat{\theta}}{\arg \min \operatorname{RMSE}(\hat{\theta}) .}
\end{gathered}
$$

Here $\hat{y}^{t t-1}$ is the forecast for information at time $t-1$ (i.e., up to the value $y^{t-1}$ and $u^{t-1}$ ) of the output vector at the next moment. Calculations done at PTC Mathcad Prime.

We select the fitting window in the middle of the data time series, leaving the beginning and the end to check the adequacy of the model. $T l=13$ (01.02.2016), $T u=51$ (01.03.2019) (see Fig. 1).

For the random walk model (when the previous value is the prediction) $R M S E=1150$ billion RUB.

Models in the enhancement order:

If we assume that deposits are unchanged (only the ruble is recalculated in accordance with exchange rate, only the first and last terms are in the right-hand sides of (1) and (2) ), then RMSE $=1028$ billion RUB, small observation errors (estimate $\sigma v_{0}=28$ billion RUB) will ensure coincidence with a slight increase in ruble deposits. Thus, observing only $M 2$ and M4, it might be assumed that nothing is happening in the country at all (though with a poor forecast error RMSE).

If we connect the trade in goods, which causes a slight departure of rubles and a significant influx of currency (see Fig. 3, 4), then $R M S E=1102$ billion RUB, and $\sigma \delta_{1}=\$ 840$ billion, which indicates large unaccounted terms in the balance of currency deposits. 
If we add time-varying flows (3) - (5) with $\beta_{0}=\beta_{2}=\beta_{3}=0$ (regardless of the change in the dollar exchange rate), $\beta_{1}=0$ too, then $R M S E=855.7$ billion RUB, $D A^{t}-$ the departure of the currency abroad repeats its smoothed arrival from trade, $R A^{t}$ - the last 4 years are almost constant about $\$ 5, D R^{t}$ about (-\$1) billion.

If the flows are associated with changes in the dollar rate, then RMSE $=788.9$ billion RUB.

The last clarification includes the dependence of dollar deposits on the $\triangle R E S 0^{t}$ - increase in international reserve assets of the Russian Federation. RMSE turned out to be equal to 754.5 billion RUB, which corresponds to the average accuracy of forecasts of masses M2 and M4 in 1.4 and $0.9 \%$, respectively. See Fig. 1. The behavior of the training curve shows that not all mechanisms for changing money supply (especially M2) are taken into account by the model. The shape of the dashed curve characterizes the adequacy of the model.

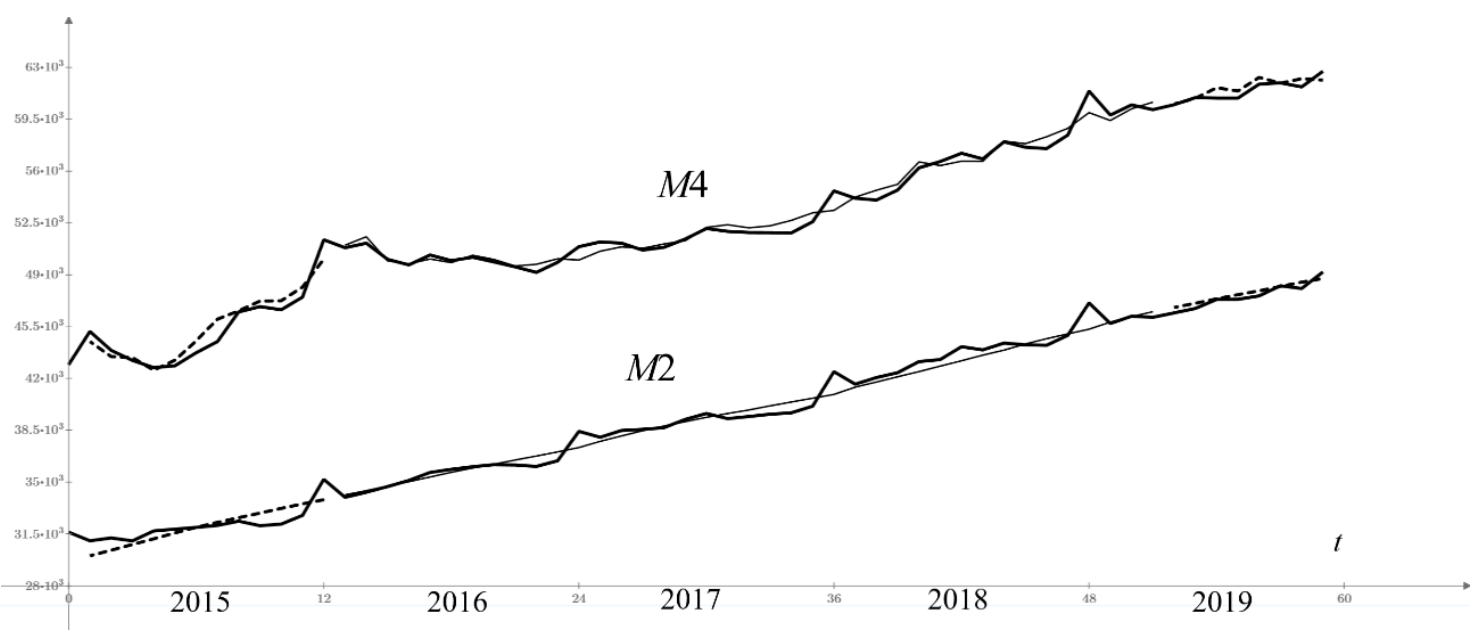

Figure1.Monthly data from 01.01.2015 to 01.12 2019. Observed money supplies (solid curve), adjusted forecast based on information a month ago (thin solid curve - training), forecast based on the estimated model (dashed curve), billion RUB.

The estimated parameters (6) $\beta_{0}=0.002, \beta_{2}=0.133, \beta_{3}=0.111$ show that with an increase / decrease in the dollar exchange rate by 1 RUB per month, for the same month:

- increases/decreases by $\$ 0.002$ billion purchase of currency for rubles abroad (direction is associated with the habit of panic, purchase volumes are small, in the last 2 years negative, i.e. there is a purchase of rubles at $\$ 0.13$ billion per month),

- decreases/increases by $\$ 0.111$ billion currency outflow (why export if it is more valuable to use here),

- decreases/increases by $\$ 0.133$ billion the creation of ruble deposits and the coming of rubles from outside. This can be explained by the fact that the creation of ruble deposits to a large extent takes place for the purchase of cheaper currency, and the arrival of non-residents' rubles falls when the ruble assets rise in price with the growth of the dollar.

The last connection is evidenced by the estimate of the correlation coefficient of the dollar rate $S$ and the Moscow Exchange index IMOEX. According to monthly data from 01.01.1998 to 01.08.2019, it is 0.692 , the significance level $(s l)$ by $t$-criterion is equal to $0.00000 \ldots$. And, when the index lags from the rate, the connection is stronger than in reverse lag (see Fig. 2), i.e. a change in rate precedes an index change. 


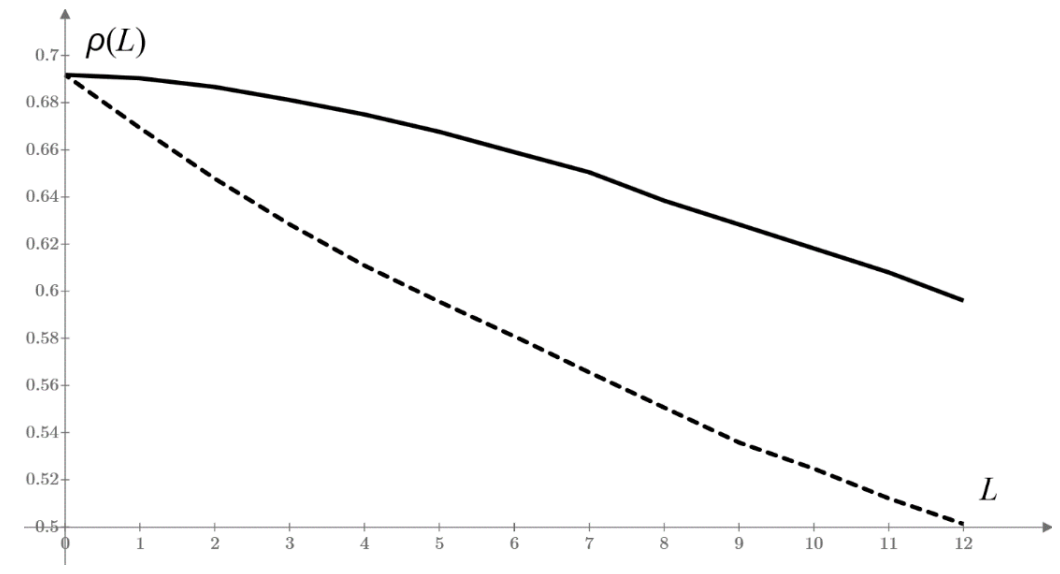

Figure 2. Estimates of the correlations of the dollar exchange rate $S$ and $\operatorname{IMOEX} \rho(L)$ for various $L$ - lags (solid curve) and advances (dashed curve) of the index.

$\beta_{1}=0.759$, i.e. $1 /\left(1+\beta_{1}\right)=0.568-$ the share of income from sales abroad (not taken into account in foreign trade in goods) going to the international reserves of the Russian Federation (an example is the "budget rule"). $\sigma v_{0}=26.7$ billion RUB $(\approx 0.05 \%)$ - an estimate of the error in observing money supply, other errors are insignificant.

Estimated currency flows see in Fig. 3. There is also a balance of currency flows in trade (actually income $\left.0.856 \mathrm{ex}^{t}-0.69 \mathrm{im}^{t}\right)$ for comparison.

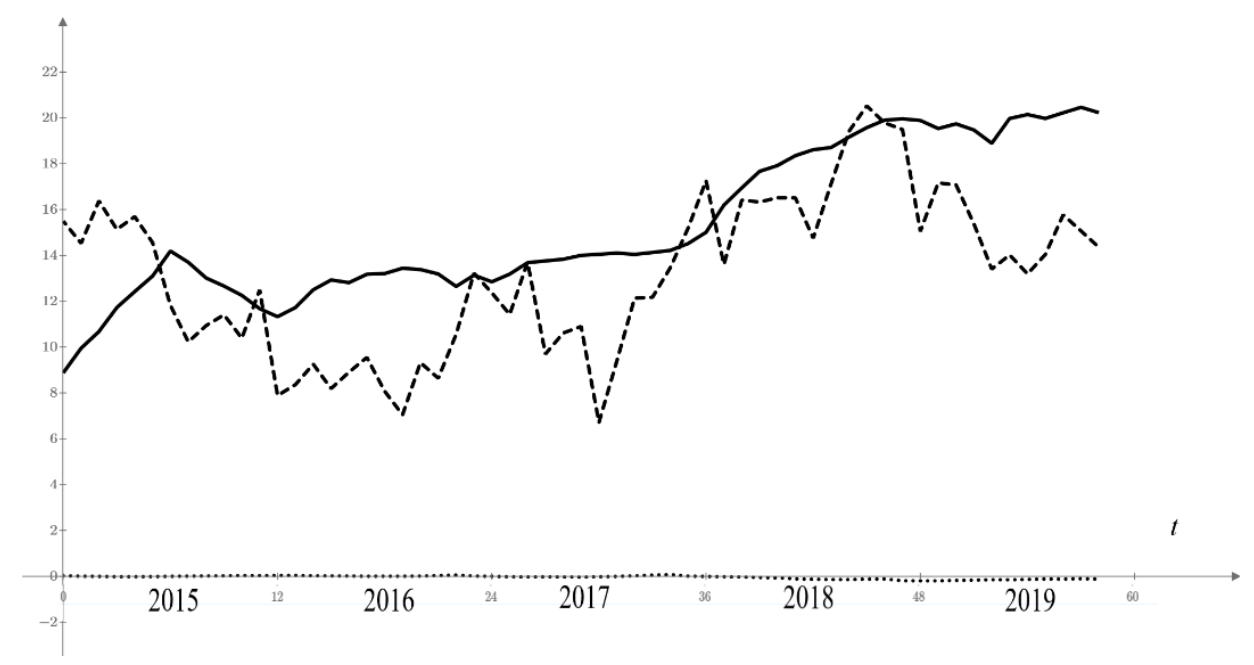

Figure 3. Indicators for the month from 01.01.2015 to 01.11 2019 billion USD. Departure of the currency abroad $D A^{t}$ (solid curve), arrival of currency during trade (dashed curve), purchase of currency for rubles from abroad $D R^{t}$ (dotted curve).

The departure of foreign currency includes, in particular, travels and trade in services, for example, according to the Central Bank of the Russian Federation in $2017 \approx \$ 5$ billion per month. You can see a large outflow of currency abroad in 2016 and 2019, which is not trade-backed.

Estimated ruble flows see in Fig. 4. There is also a balance of ruble flows in trade (actually leaving $\left.\left(0.31 \operatorname{im}^{t}-0.144 \operatorname{ex}^{t}\right) \frac{S^{t}+S^{t+1}}{2}\right)$. 


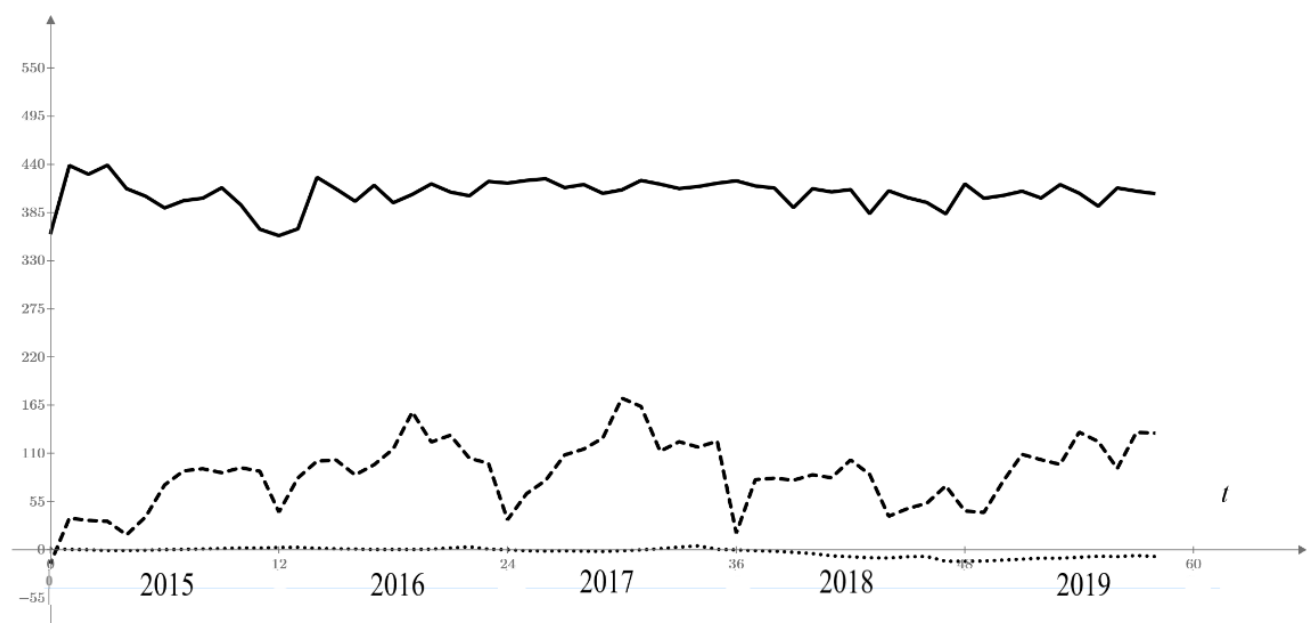

Figure 4. Indicators for the month from 01.01.2015 to 01.112019 billion RUB. Creation of deposits and the arrival of rubles from the outside ( $R A^{t}$ in rubles - a solid curve), the departure of rubles in trade (dashed curve), the purchase of foreign currency for rubles from abroad ( $D R^{t}$ in rubles - a dotted curve).

If we assume that the rubles that went away during the trade all come back, then subtracting them from $R A^{t}$, we get the volume of deposits creation - about 300 billion RUB per month. These values require further model decomposition into loans with different maturities.

\section{CONCLUSION}

The work obtained evidence that the main drivers of cross-border flows of rubles and currency, in addition to trade, are the currency/ruble exchange rate and, not taken into account in trade, the country's super-revenues. Measures of their influence on the money supply in Russia are found. Results on individual money flows in rubles and currency require comparison with the corresponding inaccessible statistics of the Central Bank of the Russian Federation.

\section{REFERENCES}

1. Statistical Bulletin of the Bank of Russia, No. 1 (320), “AEI PRIME” JSC, 2020.

2. Michael McLeay, Amar Radia and Ryland Thomas, Money creation in the modern economy. Bank of England Quarterly Bulletin, v. 54, No. 1, p. 14-27, 2014.

3. https://www.rbc.ru/economics/26/02/2020/5e55460d9a79472e99363438

4. http: // www. http://www.cbr.ru/statistics/

5. S. M. Borodachev, GDP and efficiency of Russian economy. AIP Conference Proceedings, v. 1926, 020011; doi: 10.1063 / 1.5020460, 2018.

6. S. M. Borodachev, The impact of the dollar rate on fluctuations of ruble liquidity in Russia. Preprints (www.preprints.org), doi: 10.20944 / preprints201904.0199.v1, 2019.

7. S. M. Borodachev, Estimation of the parameters of economic systems by the Kalman filter. Theoretical and Applied Economics, No. 1, p. 93-97; doi: 10.25136 / 2409-8647.2019.1.21085, 2019. 